\title{
Dominance variance: associations with selection and fitness
}

\author{
PETER CRNOKRAK* \& DEREK A. ROFF \\ Department of Biology, McGill University, 1205 Dr. Penfield Avenue, Montreal, Quebec, Canada H3A $1 B 1$
}

\begin{abstract}
Strong directional, and to some degree stabilizing, selection usually erodes only additive genetic variance while not affecting dominance variance. Consequently, traits closely associated with fitness should exhibit high levels of dominance variance. In this study we compile a large number of estimates of dominance variance to determine if traits that are subject to strong selection and/or are closely associated with fitness have higher levels of dominance variance than traits less subject to selection pressure. Estimates were taken from the literature for both wild and domestic species and each group was treated separately. Traits closely associated with fitness (life history) had significantly higher dominance components than did traits more distantly related to fitness (morphology) for wild species. No significant differences were found between life history and morphological traits for domestic species. Traits that were known to have been subject to intense directional selection (morphological traits for domestic species) had significantly higher dominance estimates than did traits that were assumed not to have been subject to strong selection (morphological traits for wild outbred species). The results are discussed with respect to the maintenance of heritable variation and the bias introduced in the calculation of the full-sib heritability estimate by high levels of dominance variance.
\end{abstract}

Keywords: dominance variance, fitness, genetic variation, selection.

\section{Introduction}

The genetic architecture of a quantitative trait is composed of additive $\left(V_{\mathrm{a}}\right)$, dominance $\left(V_{\mathrm{d}}\right)$, epistatic $\left(V_{\mathrm{i}}\right)$ variance and interactions of all three components (Bulmer, 1985). Of most importance to the transmission of a trait from one generation to the next and for predicting the short-term response to selection is the narrow sense heritability, $h^{2}$, the ratio of additive variance to phenotypic variance. Dominance variance is generally not considered important as it does not predict the response to selection (Fisher, 1930; Lynch, 1994). However, dominance variance can affect the heritability of traits during bottleneck events where nonadditive genetic variance (both dominance and epistatic) can be 'converted' into or affect additive genetic variance and therefore become available for selection to act upon (for a review see Carson, 1990). General patterns of dominance variance have been predicted by a number of theoreticians (Lynch, 1994); although mechanisms of the evolution of genetic dominance are different among the theories, all

\footnotetext{
${ }^{*}$ Correspondence.
}

agree that traits closely associated with fitness should exhibit high levels of dominance variance. Despite this, few studies have examined the prevalence of dominance variance in traits of evolutionary significance and how selection influences the level of dominance for traits closely and more distantly related to fitness.

Strong directional selection (and to a lesser degree, stabilizing selection; Lee \& Parsons, 1968; Lacy, 1987) is predicted to erode additive genetic variance and, subsequently, decrease the heritability of a trait (Felsenstein, 1965; Lande, 1988; Turelli, 1988; Gomez-Raya \& Burnside, 1990; Villanueva \& Kennedy, 1990; references in Arnold, 1990 and Garland \& Bennett, 1990; for a review see Rose et al., 1987). As a consequence, the response to selection will be reduced (but the reduction in response may result from other factors: see Falconer (1989) and Lande (1988)). Traits for a population at equilibrium are predicted to have low additive genetic variance as it is assumed that selection has moulded them to an optimum (Hegmann \& Dingle, 1982; Lynch \& Sulzbach, 1984; but see Charlesworth (1987) for an alternative explanation). Because they are assumed to be subject to intense selection, traits 
most closely associated with fitness are predicted to have low heritabilities and subsequently relatively high dominance components (Wright, 1929; Haldane, 1932; Lerner, 1954; Fisher, 1958). A number of studies (Mousseau \& Roff, 1987; Roff \& Mousseau, 1987; Garland et al., 1990; Willis et al., 1991; Partridge, 1994) have shown that life history traits, which are assumed to be closely connected to fitness, have low heritabilities while morphological traits, which are assumed to be more distantly related to fitness, have high heritabilities (behavioural and physiological traits are usually intermediate to the above two types of traits). Because selection usually erodes only additive genetic variance (Lynch, 1994), although changes in gene frequency may also cause changes in nonadditive variance as well, one would predict that the opposite pattern should be found in terms of dominance variance: life history traits should have relatively high levels of dominance variance while morphological traits should have low levels of dominance variance. In addition to eroding additive variance, selection is also expected to act directly on genetic dominance, resulting in a further relative increase of dominance variance to total genetic variance (Mather, 1979; Lynch, 1994). Fisher's (1958) theory predicts that dominance will evolve in both magnitude and direction of increasing fitness. Although Fisher's theory of the evolution of dominance has been strongly criticized (for a review see Charlesworth, 1979), empirical investigations have confirmed the last point (Breese \& Mather; 1960; Kearsey \& Kojima, 1967; Lynch, 1994 and references therein). On a per species basis, few studies exist that have examined changes that occur as a result of selection acting on the genetic architecture of quantitative traits. For the most part, strong selection does decrease additive variance and, in most cases, heritability, although in some cases the decreases are relatively small (Kaufman et al., 1977; Enfield, 1980). Discrete traits such as dimorphisms that are controlled by some underlying normally distributed variable, when subject to strong directional selection may not experience an appreciable decrease in genetic variance because the intensity of selection declines very quickly over time (Roff, 1994).

Short compilations have been made of patterns of dominance and nonadditive variance in the past but these have been either qualitative (Kearsey \& Kojima, 1967) or have reported quantitative results of only a few traits for a few species (see Garland, 1994 for a review). This study is the first to attempt a compilation of a large number of estimates con- cerning the relative distribution of dominance variance across traits that are associated with fitness and/or subject to selection to different degrees.

The present study addresses two main questions. (i) How does the relative contribution of dominance variance change from one trait-type to another? Do traits that are closely associated with fitness have relatively high levels of $V_{\mathrm{d}}$ as predicted from theory? (ii) Do patterns of $V_{\mathrm{d}}$ change from wild outbred species to domestic species for particular trait categories? Although we have no studies that have examined what changes occur in the genetic architecture of a trait in the presence of selection for a wide variety of traits and species, the above comparison will allow us at least to speculate how strong directional selection can change the relative contribution of $V_{\mathrm{a}}$ and $V_{\mathrm{d}}$ to the genetic variance of a trait.

\section{Materials and methods}

\section{Estimates of dominance variance}

Three hundred and thirty-eight estimates of dominance variance were obtained from 55 sources; 17 wild outbred species and 21 domestic species. Species were classified as domestic if they had been subject to long-term deliberate artificial selection and usually included species of economic importance such as Zea mays. The relative contribution of dominance variance to the genetic variance of a trait was calculated in two ways: (i) dominance variance as a function of the sum of dominance and additive variance:

$$
D_{\alpha}=\frac{V_{\mathrm{d}}}{V_{\mathrm{d}}+V_{\mathrm{a}}},
$$

and (ii) dominance variance as a function of phenotypic variance:

$$
D_{\beta}=\frac{V_{\mathrm{d}}}{V_{\mathrm{p}}} \text {. }
$$

The variable $D_{\alpha}$ was used to assess the relative contributions of dominance and additive variances irrespective of the phenotypic variance for a trait. Although selection may affect $V_{\mathbf{p}}$ (Hayashi \& Ukai, 1994), most interest lies in how it affects the genetic architecture of a trait. Nevertheless, a high level of $V_{\mathrm{d}}$ may be inconsequential to a trait if it is small compared with $V_{\mathrm{p}}$; for this reason, we also used the variable $D_{\beta}$. Negative variance estimates reported in the literature were standardized to zero (Kendall \& 
Stuart, 1979). We obtained 232 estimates of $D_{\alpha}$ and 106 estimates of $D_{\beta}$. For those studies that reported more than one estimate of dominance variance for each trait (repeated trials or measures under different conditions) we used the mean. A list of species, estimates and references is available from the corresponding author upon request. This is the most extensive compilation of this sort to date: it is representative but not exhaustive.

Estimates were categorized as belonging to one of four groupings: (i) behavioural traits; (ii) life history traits; (iii) morphological traits; and (iv) physiological traits. Although somewhat ambiguous in some cases, we restricted life history traits to those traits that are thought to be most closely associated with fitness. For example, life history traits included development time, flowering time and lifetime fecundity. Morphological traits referred to metric size or quality measurements such as body weight, bill colour and seed weight. Examples of behavioural traits are proboscis extension behaviour, locomotion rate and escape-avoidance conditioning. Physiological traits included both metabolic processes such as freezing resistance, and the biochemical composition of substances such as seed protein content.

The analysis addressed two main questions. (1) Are there differences between trait categories for both measures of dominance? In conjunction, are the estimates biased because of over-representation of species and/or characters? If this is the case, then if significant differences exist between life history and morphological traits, are they maintained after correction for this bias? (2) Are there statistical differences between wild and domestic species in terms of the relative importance of dominance variance for complementary trait categories?

\section{Statistical analysis and results}

\section{Predictions}

Although a number of different theories exist to explain the evolution of genetic dominance, most agree that traits associated with fitness will tend to exhibit relatively high levels of dominance variance (Fisher, 1928; Wright, 1929; Haldane, 1932; Dobzhansky, 1952; Lerner, 1954; Kacser \& Burns, 1981). Consequently, one would expect that life history traits, as they are closely related to fitness, should exhibit high levels of dominance variance in wild populations. Low levels of dominance variance are predicted for traits distantly related to fitness such as morphological traits. From previous theoretical (Lee \& Parsons, 1968) and empirical (Falconer,
1981, table 10.1, p. 150; Mousseau \& Roff, 1987) investigations concerning the relationship between fitness and heritability estimates, one would expect that behavioural and physiological traits should fall between life history and morphological traits (Roff \& Mousseau, 1987). For behavioural traits at least, this is a valid assumption as Lee \& Parsons (1968) proposed that such traits will be subject to strong stabilizing selection which would thus decrease heritability estimates for this class of traits. Making predictions about domestic species is more difficult as most were subject to strong directional selection at some point. Because of this, the only a priori prediction concerning dominance variance is that traits that are known to have been subject at one time to strong directional selection should exhibit high levels of dominance variance. The domestic data set is composed mostly of morphological traits indicating the importance of these traits in domestic breeding programmes. We therefore predict that morphological traits for domestic species should exhibit much higher levels of genetic dominance than such traits in wild outbred species.

\section{Dominance variance and fitness}

Because the reported estimates of $D_{\alpha}$ and $D_{\beta}$ are proportions, they probably violate the assumptions of parametric analysis (Sokal \& Rohlf, 1981). We therefore used nonparametric analyses to test for differences between trait categories. For the following analyses wild and domestic species were treated separately. Statistical tests for differences of estimates of dominance variance across trait categories were conducted by using the Kolmogorov-Smirnov \& Kruskal-Wallis tests (Wilkinson, 1990). In addition parametric ANOVA and Tukey HSD tests were used but the results for these were only reported when they differed from the above tests.

Wild outbred species Table 1(a) gives the results of the nonparametric tests conducted for wild outbred species for both measures of dominance $\left(D_{\alpha}\right.$ and $\left.D_{\beta}\right)$. For the variable $D_{\alpha}$, significant differences exist between different trait categories: Kruskal-Wallis test $\left(D_{\alpha}: \quad H=15.394, \quad P<0.002, \quad n=75 ; \quad D_{\beta}\right.$ : $H=6.003, P<0.111, n=60)$ and the KolmogorovSmirnov test (Table 1a). Life history traits had significantly larger dominance components than did behavioural, physiological and morphological traits (see Table 1a, and Fig. 1a for the cumulative distributions). Behavioural and physiological traits, although not statistically different from morphological traits, had means that fell between life history 
Table 1 Summary of descriptive statistics and Kolmogorov-Smirnov tests for the variables $D_{\alpha}$ (below diagonal) and $D_{\beta}$ (above diagonal) for wild outbred and domestic species

\begin{tabular}{|c|c|c|c|c|}
\hline & Life history & Behaviour & Physiology & Morphology \\
\hline \multicolumn{5}{|c|}{$\begin{array}{l}\text { (a) Wild outbred species } \\
D_{\alpha}\end{array}$} \\
\hline$n$ & 22 & 12 & 18 & 26 \\
\hline $\begin{array}{l}\bar{x} \pm \mathrm{SE} \\
D_{\beta}\end{array}$ & $0.544 \pm 0.072$ & $0.237 \pm 0.061$ & $0.266 \pm 0.068$ & $0.166 \pm 0.036$ \\
\hline$n$ & 20 & 2 & 16 & 24 \\
\hline $\bar{x} \pm \mathrm{SE}$ & $0.313 \pm 0.069$ & $0.040 \pm 0.020$ & $0.209 \pm 0.072$ & $0.133 \pm 0.035$ \\
\hline \multicolumn{5}{|c|}{ Kolmogorov-Smirnov $P$-value (Tukey HSD) } \\
\hline Life history & - & 0.600 & $0.023(0.616)$ & 0.116 \\
\hline Behaviour & $0.030(0.011)$ & - & 1.000 & 1.000 \\
\hline Physiology & $0.040(0.008)$ & 0.326 & - & 0.464 \\
\hline Morphology & 0.0001 & 0.424 & 0.189 & - \\
\hline \multicolumn{5}{|c|}{ (b) Domestic species } \\
\hline$n$ & 24 & & 29 & 101 \\
\hline $\begin{array}{l}\bar{x} \pm \mathrm{SE} \\
D_{\beta}\end{array}$ & $0.392 \pm 0.058$ & & $0.479 \pm 0.059$ & $0.422 \pm 0.028$ \\
\hline$n$ & 6 & & 10 & 28 \\
\hline $\bar{x} \pm \mathrm{SE}$ & $0.040 \pm 0.026$ & & $0.307 \pm 0.081$ & $0.190 \pm 0.033$ \\
\hline \multicolumn{5}{|c|}{ Kolmogorov-Smirnov $P$-value } \\
\hline Life history & - & & $0.038(0.025)$ & $0.011(0.196)$ \\
\hline Physiology & 0.424 & & - & 0.181 \\
\hline Morphology & 0.901 & & 0.531 & - \\
\hline
\end{tabular}

Where ANOVA tests revealed results different from the $\mathrm{K}-\mathrm{S}$ test the values are given in parentheses (Tukey HSD comparisons).

and morphology traits. No significant differences were found between trait categories for the variable $D_{\beta}$ except for the paired comparison KolmogorovSmirnov test between life history and physiology. Although having lower mean values, $D_{\beta}$ estimates were comparable to $D_{\alpha}$ estimates for all categories except behaviour (but this may result from the low sample size of two). The parametric and nonparametric tests agree for the most part except for the comparison between life history and physiological traits for $D_{\beta}$ (see Table 1a), in which the nonparametric tests show significance but the parametric do not, suggesting differences in the shape of the curve.

Domestic species Table 1(b) presents the results of the nonparametric tests for domestic species. As no estimates were available for behavioural traits, no comparisons between this trait and the other three were possible. No significant differences were found between trait categories for the variable $D_{\alpha}$ (Krus-
kal-Wallis test: $H=1.167, P<0.558, n=155)$. A significant difference was found for $D_{\beta}$ (KruskalWallis test: $H=8.844, P<0.012, n=45$ ); life history traits had significantly lower dominance components than did physiological traits (see Table 1b).

\section{Analysis of study means}

The above analysis may be biased because of the disparity in the number of estimates reported for each study (i.e. differences may result from one study with an inordinately large number of estimates). To circumvent this problem, we used single estimates for each trait category from each study. Where more than one estimate was reported for each trait-type (eg. morphology) for a given study, an average was used. This was done for estimates calculated using the variable $D_{\alpha}$ only, as not enough estimates were available for $D_{\beta}$. Kolmogorov-Smirnov and Kruskall-Wallis tests were used to deter- 


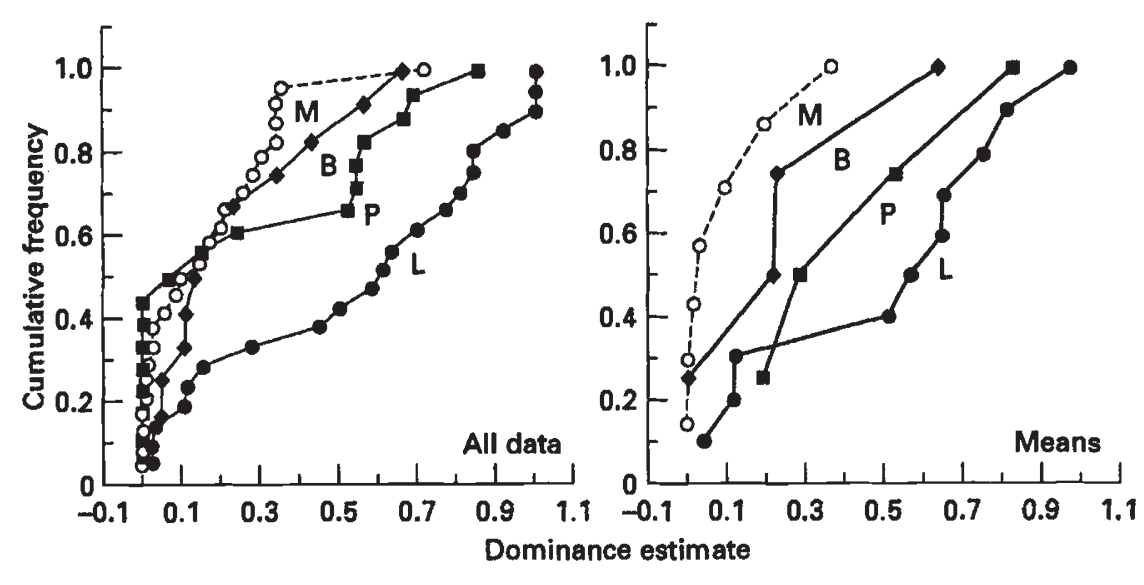

Table 2 Summary of descriptive statistics and Kolmogorov-Smirnov test for study means using the variable $D_{\alpha}$ for wild outbred (below diagonal) and domestic (above diagonal) species

\begin{tabular}{lllll}
\hline & Life history & Behaviour & Physiology & Morphology \\
\hline Wild outbred & & & & \\
$n$ & 10 & 4 & 4 & 7 \\
$\bar{x} \pm \mathrm{SE}$ & $0.585 \pm 0.095$ & $0.275 \pm 0.136$ & $0.528 \pm 0.123$ & $0.097 \pm 0.052$ \\
Domestic & & & & \\
$n$ & 14 & 0 & 21 & 22 \\
$\bar{x} \pm \mathrm{SE}$ & $0.396 \pm 0.064$ & - & $0.456 \pm 0.069$ & $0.395 \pm 0.040$ \\
$\begin{array}{l}\text { Kolmogorov-Smirnov } P \text {-value } \\
\text { Life history }\end{array}$ & - & - & & \\
$\begin{array}{l}\text { Behaviour } \\
\text { Physiology }\end{array}$ & 0.587 & - & 0.885 & 0.815 \\
Morphology & 0.745 & 0.405 & - & - \\
\hline
\end{tabular}

Fig. 1(a) Cumulative frequency distributions for all four trait categories (M: morphology; B: behaviour; P: physiology; and L: life history) for wild outbred species. (b) Cumulative frequency distributions for mean values calculated for all four trait categories from each study (M: morphology; B: behaviour; P: physiology; and $L$ : life history) for wild outbred species. mine if significant patterns still existed as compared to the above results. Table 2 and Fig. 1(b) show that the significant differences found between life history and morphology traits for the entire data set are still maintained when study means are used for wild outbred species: Kruskal-Wallis test; $H=9.879$, $P<0.020, n=27$ (see Table 2 for test statistics). As for the entire data set, the same results hold.

\section{Analysis of paired comparisons of life history and morphological traits}

To determine if the above patterns of dominance components were biased as a result of the overrepresentation of species or the over-representation of multiple traits measured for a given species, we chose individual studies that reported both life history and morphology estimates for a single species. As the only a priori prediction that can be made among the four trait categories with respect to associations with fitness is for life history and morphological traits, only these were used. We collected estimates from five wild outbred and eight domestic species. Where more than one estimate was reported for life history and morphology traits, a mean value was used in the analysis. A pairedsamples $t$-test was used to assess if the differences between life history and morphology traits were significant.

Low sample sizes prevented the calculation of mean dominance estimates for $D_{\beta}$. Paired-sample $t$ tests revealed no significant differences between mean values of life history and morphological traits for either wild or domestic species (wild: $t_{4}=-1.328, \quad P<0.255 ; \quad$ domestic: $t_{7}=-1.102$, $P<0.307)$. Although nonsignificant, the mean difference (morphology-life history) between the mean life history and morphology values for wild species 
was quite high, $D=-0.222$, and in the predicted direction (life history higher than morphological traits). Because of the low sample sizes $(n=5$ for wild outbred species and $n=8$ for domestic species), the results obtained for both data sets should be viewed with caution.

\section{Comparison of wild out bred and domestic species}

In this section, we address the question: do $D_{\alpha}$ estimates vary between wild and domestic species? Because the literature concerning domestic species is fairly well detailed, selection pressures are known. This gives us a unique opportunity to make inferences about how strong directional selection changes the genetic architecture of traits. Of particular importance in this regard is the comparison of morphological traits between wild and domestic species as it is this trait-type that is of most importance in domestic breeding programmes (sample size for morphological traits of domestic species $=101$, for all other trait categories combined $=53$ ).

An independent samples $t$-test was used to determine if there exist differences between domestic and wild species in terms of dominance variance for complementary traits. Nonparametric KolmogorovSmirnov tests were used for paired comparisons between life history, physiological and morphological traits between wild and domestic species.

Parametric independent samples $t$-tests and nonparametric Kolmogorov-Smirnov paired comparisons were conducted on the three trait categories, life history, physiology and morphology for the variable $D_{\alpha}$ only, as not enough estimates were available for $D_{\beta}$. Because a priori, we predict that domestic species estimates of dominance will be higher than wild outbred species estimates using morphological traits, the test was one-tailed. Table 3 lists the test results of the paired comparisons between wild and domestic species for both parametric and nonparametric tests: morphological traits were significantly different with estimates for domestic species being higher than wild species $\left(t_{123}=-4.069, P<0.00005\right.$, see Fig. 2 top panel), life history traits were not significantly different between wild and domestic species $\left(t_{45}=1.74, P<0.089\right.$, see Fig. 2 middle panel) and, finally, physiological traits were significantly different with estimates for domestic species being higher than wild species $\left(t_{46}=-2.532\right.$, $P<0.015$, see Fig. 2 bottom panel). The Kolmogorov-Smirnov tests tended to be more conservative than the independent samples $t$-tests where the only
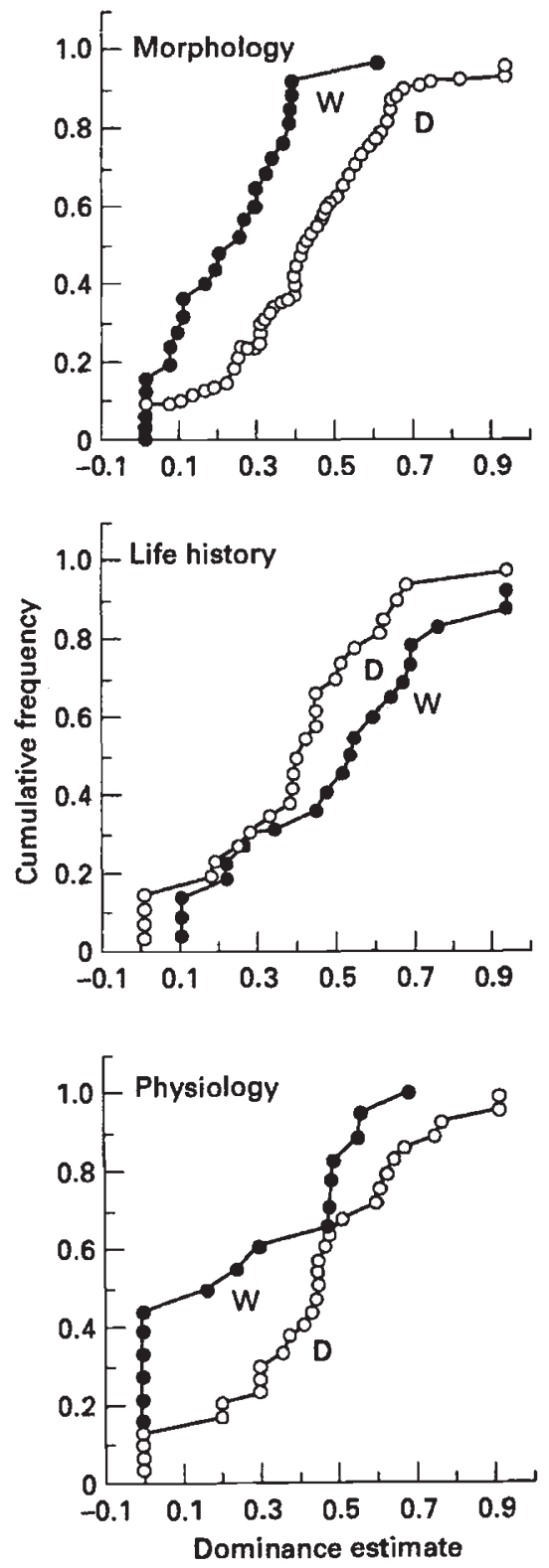

Fig. 2 Comparison of cumulative frequency distributions of wild (W) and domestic (D) species for morphological, life history and physiological trait estimates. Note: variable used here was $D_{\alpha}$.

significant difference between wild and domestic species was for morphological traits (see Table 3).

\section{Discussion}

Our analysis supports the hypothesis proposed by a number of theoreticians concerning selection and traits related to fitness outlined in the introduction of this paper (references therein). Traits closely associated with fitness (life history traits) were found 
Table 3 Summary of mean values, independent samples $t$-tests, and Kolmogorov-Smirnov tests for life history, physiology and morphology traits between wild and domestic species

\begin{tabular}{|c|c|c|c|}
\hline & $\begin{array}{c}\text { Wild outbred } \\
\bar{x} \pm S E\end{array}$ & $\begin{array}{c}\text { Domestic } \\
\bar{x} \pm \mathrm{SE}\end{array}$ & $\begin{array}{c}P \text {-value } \\
(t \text {-test })\end{array}$ \\
\hline \multicolumn{4}{|l|}{ Trait category } \\
\hline Morphology & $0.166 \pm 0.035$ & $0.422 \pm 0.028$ & $<0.00005$ \\
\hline Life history & $0.544 \pm 0.073$ & $0.392 \pm 0.058$ & 0.089 \\
\hline Physiology & $0.266 \pm 0.068$ & $0.479 \pm 0.059$ & 0.015 \\
\hline Kolmogorov-Smirnov test & \multicolumn{2}{|c|}{$D_{\max }$} & $P$-value \\
\hline Morphology & \multicolumn{2}{|c|}{0.572} & $<0.0001$ \\
\hline Life history & \multicolumn{2}{|c|}{0.316} & 0.177 \\
\hline Physiology & \multicolumn{2}{|c|}{0.336} & 0.131 \\
\hline
\end{tabular}

Note: the variable used here was $D_{\alpha}$, and the $t$-test for the morphological comparison was one-tailed.

to have significantly larger dominance variance components than traits more distantly related to fitness (morphological traits) in wild species. These differences are maintained even when mean values are used. Because of low sample size, the nonsignificant results obtained from the paired comparisons analysis of life history and morphology traits for wild species must be viewed with caution. The relative contribution to genetic variance as a result of dominance was on average higher than that of additive variance for life history traits in wild outbred species. The nonsignificant differences (both individual values and mean estimates) found between life history and morphology traits in domestic species also lends support to theory as most captive breeding programmes concentrate on morphological traits, as is evidenced by the large representation of this category of trait in the literature. Further support of the theory comes from the comparison of wild and domestic species for morphological traits alone; the significantly larger mean value of $D_{\alpha}$ in domestic species indicates that traits subject to intense selection will have a greater proportion of genetic dominance contributing to genetic variance than those that are not.

Life history traits have levels of dominance variance that on average may be as high or even higher than additive variance. Although dominance variance is inconsequential for certain methods of estimating heritability (half-sib, parent-offspring, $P O$ ), it may bias the $h^{2}$ estimate for full-sib $(F S)$ calculations. FS estimates are most commonly available for natural populations of vertebrates (Brodie \& Garland, 1994) as paternity cannot be assessed for gravid females taken from the wild. These estimates include some dominance, epistatic and commonfamily environment (maternal) effects. By standardizing the environment during rearing or using a split-cage design, one can estimate, and thus eliminate, the common family environment variance (Falconer, 1989; Arnold, 1994), but the same cannot be said of dominance variance. For a $F S$ design the resemblance between siblings is measured as the intraclass correlation, $t$ :

$t=\frac{\sigma_{\mathrm{b}}^{2}}{\sigma_{\mathrm{b}}^{2}+\sigma_{\mathrm{w}}^{2}}$,

where $\sigma_{\mathrm{b}}^{2}=$ variance between groups and $\sigma_{\mathrm{w}}^{2}=$ variance within groups. The intraclass correlation describes the average level of relatedness between members of a group. To calculate a $F S$ heritability the intraclass correlation must be multiplied by a factor of two. The FS estimate then includes (Becker, 1992):

$\frac{V_{\mathrm{a}}+\frac{1}{2} V_{\mathrm{d}}+\frac{1}{2} V_{\mathrm{i}}+2 V_{\mathrm{ec}}}{V_{\mathrm{p}}}$.

Assuming $V_{\mathrm{i}}$ (epistatic variance) and $V_{\mathrm{ec}}$ (common family environment variance) contribute little to the $h^{2}$ estimate, dominance variance may significantly bias the heritability estimate in a FS analysis. Although heritability estimates of morphological traits will probably not be strongly biased because of dominance variance, life history traits almost certainly will. With dominance variance being on average greater than additive variance (Table 1a), life history traits that have a moderate to high heritability (i.e. $h^{2}$ over 0.60 ) may have a $F S$ heritability that

(C) The Genetical Society of Great Britain, Heredity, 75, 530-540. 
is inflated by over 30 per cent (e.g. when $h^{2}=0.60$ the estimate will give $\left.h^{2}=0.90\right)$. As is evident, the FS heritability estimate does not represent pure additive genetic variance as a function of total phenotypic variance (Falconer 1989; Arnold, 1994; Garland, 1994). Despite this, Mousseau \& Roff (1987) found no significant differences between $F S$ and $P O$ regression estimates in a number of taxa. Nonetheless, their conclusions that the contribution of dominance and common environment effects are low is premature as their data set was limited primarily to morphological traits (27 of 33). Assuming low or no common environment effects, one would not expect significant differences between $F S$ and $P O$ estimates for morphological traits as dominance variance contributes little to these types of traits $\left(h^{2}\right.$ inflation because $V_{\mathrm{d}}<10$ per cent). Although it is not known to what degree total nonadditive genetic effects differ in magnitude among traits (Shwartz \& Herzog, 1994; Dohm \& Garland, 1993), the contribution of dominance variance will vary depending on the type of trait examined (this study; Dohm \& Garland, 1993). Therefore, before deciding on a particular breeding design for estimating heritabilities, it is critical to take into consideration the types of traits being measured to obtain accurate estimates.

Most researchers discount the contribution dominance plays in the genetic architecture of traits as it is only additive genetic variance that predicts the short-term response to selection. Although this is true, dominance variance can play an important role in the maintenance of additive genetic variance. Heterozygote advantage has long been recognized as a potential means by which heritable variance is maintained (Fisher, 1958; Falconer, 1981; Lacy, 1987; for a review see Futuyma, 1986; for counter arguments see Lande, 1988). With dominance and over-dominance (greater phenotypic expression of the heterozygote over both homozygotes) at a number of loci controlling a quantitative trait such as growth rate, intense directional and to some degree stabilizing selection, will not erode as much additive variance as it would if the trait were controlled by a number of alleles whose actions were purely additive (Willis \& Orr, 1993). Although in this study we report the magnitude of dominance variance and not the direction, it is not unreasonable to assume that the direction of such dominance effects would be in the direction of increasing fitness (Fisher, 1958; Lynch, 1994). The high levels of dominance variance found for life history traits could be a means by which such traits, although closely associated with fitness, may retain significant levels of additive genetic variance in the presence of selection.
The presence of high levels of dominance variance may not only be a means by which heritable variance is maintained but under certain conditions may increase the amount of additive genetic variance that is available for selection. 'Classical' theory assumes that bottleneck events are expected to decrease the additive genetic variance to a level expected from inbreeding (Crow \& Kimura, 1970; Nei et al., 1975; Lande, 1980; Falconer, 1981; Barton \& Charlesworth, 1984; Carson, 1990). Recent theoretical (Carson, 1990; Willis \& Orr, 1993) and empirical investigations (Carson \& Wissotzkey, 1989; López-Fanjul \& Villaverde, 1989; Bryant \& Meffert, 1991) have revealed that severe bottleneck events such as those where only one pregnant female survives $\left(N_{\circ}=2\right)$, may increase the level of heritable variation available for selection. Although the proposed mechanisms by which this could occur have not been empirically verified, it is assumed that the realized increase in additive genetic variance comes about by the erosion of epistatic genetic variance (through allelic fixation at regulatory loci) and the subsequent expression, and availability to selection, of previously masked additive variance (Goodnight, 1987; Cockerham \& Tachida, 1988; Tachida \& Cockerham, 1989; for a review of mechanisms see Carson, 1990). Theoretical analyses have shown that unless alleles are completely additive in their heterozygous effects, population bottlenecks will increase the additive genetic variance (and subsequently, heritability) of a trait (Robertson, 1952; Willis \& Orr, 1993). It is well known that dominance variance at many loci affects a number of fitness components (Simmons \& Crow, 1977; Crow \& Simmons, 1983; Charlesworth \& Charlesworth, 1987). In the past the erosion of epistatic variance was considered the prime cause of increase in additive genetic variance in a number of empirical studies (Bryant et al., 1986; López-Fanjul \& Villaverde, 1989). However, recent considerations have now placed a greater importance on the effects of genetic dominance acting through changes in gene frequency as the cause (Willis \& Orr, 1993). Although such effects may be transient, the high estimates of dominance variance we found in wild species for life history traits may have profound effects on the heritability of such traits during extreme selection events such as occur in population bottlenecks.

Fisher's view that traits closely associated with fitness should exhibit low levels of additive genetic variance has been widely interpreted to mean low heritabilities (Falconer, 1981; Mousseau \& Roff, 1987). This interpretation has been empirically verified (Mousseau \& Roff, 1987; Roff \& Mousseau, 
1987). Fisher postulated that differences between heritabilities among trait categories are the result of differences in additive genetic variance, but recent theoretical considerations by Price \& Schluter (1991) contest this idea. They propose that the reason life history traits have low heritabilities is because such traits are composites of many morphological, physiological and behavioural traits. Because life history traits are composites of multiple underlying traits, they are subject to numerous sources of environmental variation which in turn inflates phenotypic variance, thus decreasing the heritability. This would be the case even if the selective pressures for both life history and morphological traits were the same (Price \& Schluter, 1991). To resolve this issue, one needs to examine the changes that occur in life history and morphological traits under selection for a number of generations for a large number of species. This is, at this time, an unrealistic goal. The next best thing would be to examine the relative differences that exist in the genetic components of traits for both life history and morphology traits. Although differences may exist in terms of phenotypic variance (irrespective of genetic variance) between morphological and life history traits, our data set reveals that significant differences also exist in the genetic parameters of the traits exclusive of $V_{\mathrm{p}}$ (variable $D_{\alpha}$ in Table 1a and Fig. 1). Although these results do not rule out the possibility put forth by Price \& Schluter, they suggest that selection on traits closely associated with fitness will tend to change the relative contribution of additive and dominance variance in the genetic architecture of traits, and therefore lend support to Fisher's theory.

\section{Acknowledgments}

We thank Y. Carrière, R. Preziosi, G. Sterling, Y. Tanaka, I. Weigensberg and two annonymous reviewers for their comments on earlier versions of this paper. This study was supported by a grant to D.A.R. from the National Sciences and Engineering Council of Canada.

\section{References}

ARNOLD, S. J. 1990. Inheritance and the evolution of behavioral ontogenies. In: Hahn, M. E., Hewitt, J. K., Henderson, N. D. and Benno, R. H. (eds) Developmental Behavior Genetics: Neural, Biometrical, and Evolutionary Approaches, pp. 167-189. Oxford University Press, New York.

ARNOLD, S. J. 1994. Multivariate inheritance and evolution: a review of concepts. In: Boake, C. R. B. (ed.) Quanti- tative Genetic Analysis of the Evolution of Behavior, pp. 17-48. University of Chicago Press, Chicago.

BARTON, N. H. AND CHARLESWORTH, B. 1984. Genetic revolutions, founder events and speciation. Ann. Rev. Ecol. Syst., 15, 133-164.

BECKER, w. A. 1992. Manual of Quantitative Genetics, 5th edn. Academic Enterprises, Washington.

BREESE, E. L. AND MATHER, K. 1960. The organization of polygenic activity within a chromosome in Drosophila. II. Viability. Heredity, 14, 375-399.

BRODIE, E. D. AND GARLAND, T., Jr. 1994. Quantitative genetics of snake populations. In: Seigel, R. A. and Collins, J. T. (eds) Snakes: Ecology and Behavior, pp. 315-362. McGraw-Hill, New York.

BRYANT, E. H., McCOMMASS, S. A. AND COMBS, L. M. 1986. The effect of an experimental bottleneck upon quantitative genetic variation in the housefly. Genetics, 114, 1191-1211.

BRYANT, E. H. AND MEFFERT, L. M. 1991. The effects of bottlenecks on genetic variation, fitness, and quantitative traits in the housefly. In: Dudley, E. C. (ed.) The Unity of Evolutionary Biology, Proceedings of the Fourth International Congress of Systematics and Evolutionary Biology, pp. 591-601. Dioscorides Press, Portland, OR.

BULMER, M. G. 1985. The Mathematical Theory of Quantitative Genetics. Clarendon Press, Oxford.

CARSON, H. L. 1990. Increased genetic variance after a population bottleneck. Trends Ecol. Evol., 5, 228-230.

CARSON, H. L. AND WISOTZKY, R. G. 1989. Increase in genetic variance following a population bottleneck. $\mathrm{Am}$. Nat., 134, 668-673.

CHARLESWORTH, B. 1979. Evidence against Fisher's theory of dominance. Nature, 278, 848-849.

CHARLESWORTH, B. 1987. The Heritability of Fitness. In: Bradbury, J. W. and Andersson, M. B. (eds) Sexual Selection: Testing the Alternatives, pp. 21-40. Dahlem Workshop on Sexual Selection. John Wiley and Sons, Chichester.

CHARLESWORTH, D. AND CHARLESWORTH, B. 1987. Inbreeding depression and its evolutionary consequences. Ann. Rev. Ecol. Syst., 18, 237-268.

COCKERHAM, C. C. AND TACHIDA, H. 1988. Permanency of response to selection for quantitative characters in finite populations. Proc. Natl. Acad. Sci. U.S.A., 85, 1563-1565.

CROW, J. F. AND Kimura, M. 1970. An Introduction to Population Genetics Theory. Harper and Row, New York.

CROW, J. F. AND SIMMONS, M. J. 1983. The mutation load in Drosophila. In: Ashburner, M., Carson, H. L. and Thompson, J. N., Jr. (eds) The Genetics and Biology of Drosophila, vol. 3c, pp. 2-35. Academic Press, London.

DOBZHANSKY, Th. 1952. Nature and origin of heterosis. In: Gowen, J. W. (ed.) Heterosis, pp. 218-223. Iowa State College Press, Ames, IA.

DOHM, M. R. AND GARLAND, T., Jr. 1993. Quantitative genetics of snake counts in the garter snake Thamnophis sirtalis. Copeia, 4, 987-1002.

ENFIELD, F. D. 1980. Long-term effects of selection: the limits to response. Proceedings of the Symposium on

(c) The Genetical Society of Great Britain, Heredity, 75, 530-540. 
Selection Experiments in Laboratory and Domestic Animals, pp. 69-86. Commonwealth Agricultural Bureau, Slough.

FALCONER, D. S. 1981. Introduction to Quantitative Genetics, 2nd edn. Longman, London.

FALCONER, D. S. 1989. Introduction to Quantitative Genetics, 3rd edn. John Wiley and Sons, New York.

FELSENSTEIN, J. 1965. The effect of linkage on directional selection. Genetics, 52, 349-363.

FISHER, R. A. 1928. The possible modification of the response of wild type to recurrent mutations. Am. Nat., 62, 115-126.

FISHER, R. A. 1930. The Genetical Theory of Natural Selection. Clarendon Press, Oxford.

FISHER, R. A. 1958. The Genetical Theory of Natural Selection, 2nd edn. Dover Publications, New York.

FutuYMA, D. J. 1986. Evolutionary Biology, 2nd edn. Sinauer Associates, Sunderland, MA.

GARLAND, T., Jr. 1994. Quantitative genetics of locomotor behavior and physiology in a garter snake. In: Boake, C. R. B. (ed.) Quantitative Genetic Studies of Behavioral Evolution, pp. 251-277. University of Chicago Press, Chicago.

GARLAND, T., Jr. AND BENNETT, A. F. 1990. Quantitative genetics of maximal oxygen consumption in a garter snake. Am. J. Physiol., 259, R986-R992.

GARLAND, T., Jr., BENNETT, A. F. AND DANIELS, C. B. 1990. Heritability of locomotor performance and its correlates in a natural population. Experientia, 46, 530-533.

GOMEZ-RAYA, L. AND BURNSIDE, E. B. 1990. The effect of repeated cycles of selection on genetic variance, heritability, and response. Theor. Appl. Genet., 79, 568-574.

GOODNIGHT, C. J. 1987. On the effect of founder events on epistatic genetic variance. Evolution, 41, 80-91.

HALDANE, J. B. s. 1932. The Causes of Evolution. Longmans, Green \& Co., New York.

HAYASHI, T. AND UKAI, Y. 1994. Change in genetic variance under selection in a self-fertilizing population. Genetics, 136, 693-704.

HEGMANN, J. AND DINGLE, H. 1982. Phenotypic and genotypic covariance structure in milkweed bug life history traits. In: Dingle, H. and Hegmann, J. (eds) Evolution and Genetics of Life Histories, pp. 177-186. Springer, New York.

KACSER, H. AND BURNS, J. A. 1981. The molecular basis of dominance. Genetics, 97, 639-666.

KAUFMAN, P. K., ENFIELD, F. D. AND COMSTOCK, R. E. 1977. Stabilizing selection for pupa weight in Tribolium castaneum. Genetics, 87, 327-341.

KEARSEY, M. J. AND KOJIMA, K. 1967. The genetic architecture of body weight and egg hatchability in Drosophila melanogaster. Genetics, 56, 23-37.

Kendall, M. AND STUART, A. 1979. The Advanced Theory of Statistics. II. Inference and Relationship, 4th edn. Macmillan, New York.

LACY, R. C. 1987. Loss of genetic diversity from managed populations: interacting effects of drift, mutation, immigration, selection, and population subdivision. Conserv. Biol., 1, 143-158.
LANDE, R. 1980. Genetic variation and phenotypic evolution during allopatric speciation. Am. Nat., 116, 463-479.

LANDE, R. 1988. Quantitative genetics and evolutionary theory. In: Weir, B., Eisen, E., Goodman, M. and Namkoong, G. (eds.) Proceedings of the Second International Conference on Quantitative Genetics, pp. 71-84 Sinauer Ass., Sunderland, MA.

LEE, B. T. O. AND PARSONS, P. A. 1968. Selection, prediction and response. Biol. Rev., 43, 139-174.

LeRner, I. M. 1954. Genetic Homeostasis. Oliver \& Boyd, Edinburgh.

LÓPEZ-FANJUL, C. AND VILLAVERDE, A. 1989. Inbreeding increases genetic variance for viability in Drosophila melanogaster. Evolution, 43, 1800-1804.

LYNCH, C. B. 1994. Evolutionary inferences from genetic analysis of cold adaptation in laboratory and wild populations of the house mouse, Mus domesticus. In: Boake, C. R. B. (ed.) Quantitative Genetic Studies of Behavioral Evolution. University of Chicago Press, Chicago.

LYNCH, C. AND SULZBACH, D. 1984. Quantitative genetic analysis of temperature regulation in Mus musculus. II. Diallel analysis of individual traits. Evolution, 38, 527-540.

MATHER, K. 1979. Historical overview: quantitative variation and polygenic systems, In: Thompson, J. N., Jr. and Thoday, J. M. (eds) Quantitative Genetic Variation, pp. 5-34. Academic Press, New York.

MOUSSEAU, T. A. AND ROFF, D. A. 1987. Natural selection and the heritability of fitness components. Heredity, 59, 181-197.

Nei, M., MARUyama, T. AND CHAKRaborTy, R. 1975. The bottleneck effect and genetic variability in populations. Evolution, 29, 1-10.

PARTRIDGE, L. 1994. Genetic and non-genetic approaches to questions about sexual selection. In: Boake, C. R. B. (ed.) Quantitative Genetic Studies of Behavioral Evolution, pp. 126-141. University of Chicago Press, Chicago

PRICE, T. AND SCHLUTER, D. 1991. On the low heritability of life-history traits. Evolution, 45, 853-861.

ROBERTSON, A. 1952. The effect of inbreeding on variation due to recessive genes. Genetics, 37, 189-207.

ROFF, D. A. 1994. Evolution of dimorphic traits: effect of directional selection on heritability. Heredity, 72, 35-41.

ROFF, D. A. AND MOUSSEAU, T. A. 1987. Quantitative genetics and fitness: lessons from Drosophila. Heredity, 58, $103-118$.

ROSE, M. R., SERVICE, P. M. AND HUTCHINSON, E. W. 1987. Three approaches to trade-offs in life history evolution. In: Loeschcke, V. (ed.) Genetic Constraints on Adaptive Evolution, pp. 91-105. Springer, Berlin.

SCHWARTZ, J. M. AND HERZOG, H. A. 1994. Estimates of heritability of antipredator behaviour in three garter snake species (Thamnophis butleri, T. melanogaster, T. sirtalis) in nature. Behav. Genet., (in press).

SIMMONS, M. J. AND CROW, J. F. 1977. Mutations affecting fitness in Drosophila populations. Ann. Rev. Genet., 11, 49-78.

SOKAL, R. R. AND ROHLF, F. J. 1981. Biometry, 2nd edn. 
Freeman, San Francisco.

TACHIDA, H. AND COCKERHAM, c. C. 1989. Effects of identity disequilibrium and linkage on quantitative variation in finite populations. Genet. Res., 53, 63-70.

TURELLI, M. 1988. Phenotypic evolution, constant covariances and the maintenance of additive variance. Evolution, 42, 1342-1347.

VILLANUEVA, B. AND KENNEDY, B. W. 1990. Effect of selection on genetic parameters of correlated traits. Theor. Appl. Genet., 80, 746-752.
WILKINSON, L. 1990. SYSTAT: The System for Statistics. SYSTAT, Evanston, IL.

WILLIS, J. H., COYNE, J. A. AND KIRKPATRICK, K. 1991. Can one predict the evolution of quantitative characters without genetics? Evolution, 45, 441-444.

wILLIS, J. H. AND ORR, H. A. 1993. Increased heritable variation following population bottlenecks: the role of dominance. Evolution, 47, 949-957.

WRight, s. 1929. Fisher's theory of dominance. Am. Nat, 63, 274-279. 